\title{
ASO Visual Abstract: Establishing Novel Molecular Subtypes of Appendiceal Cancer
}

Mary Garland-Kledzik, MD', Anthony Scholer, $\mathrm{MD}^{2}$, Miquel Ensenyat-Mendez, MS ${ }^{3}$, Javier I. J. Orozco, MD $^{4}$, Adam Khader, $\mathrm{MD}, \mathrm{PhD}^{2}$, Juan Santamaria-Barria, $\mathrm{MD}^{2}$, Trevan Fischer, $\mathrm{MD}^{2}$, Alessio Pigazzi, $\mathrm{MD}^{5}$, and Diego M. Marzese, $\mathbf{P h D}^{3}$

${ }^{1}$ Division of Surgical Oncology, West Virginia University, Morgantown, WV; ${ }^{2}$ Department of Surgery, Saint John's Cancer Institute at Providence St. John's Health Center, Santa Monica, CA; ${ }^{3}$ Cancer Epigenetics Laboratory, Health Research Institute of the Balearic Islands (IdISBa), Palma, Islas Baleares, Spain; ${ }^{4}$ Cancer Epigenetics Laboratory, Saint John's Cancer Institute at Providence St. John's Health Center, Santa Monica, CA; ${ }^{5}$ Colon and Rectal Surgery, Weill Cornell Medicine, New York-Presbyterian Hospital, New York, NY

Peritoneal carcinomatosis is a difficult disease process to treat. Finding factors predictive of longer survival and unique targets for therapy in this disease process will help personalize the role of cytoreduction and systemic therapy for these patients. The authors use the American Association of Cancer Research GENIE database (https://doi.org/ 10.1245/s10434-021-10945-8) and machine learning to identify novel genetic subtypes in appendiceal cancer.

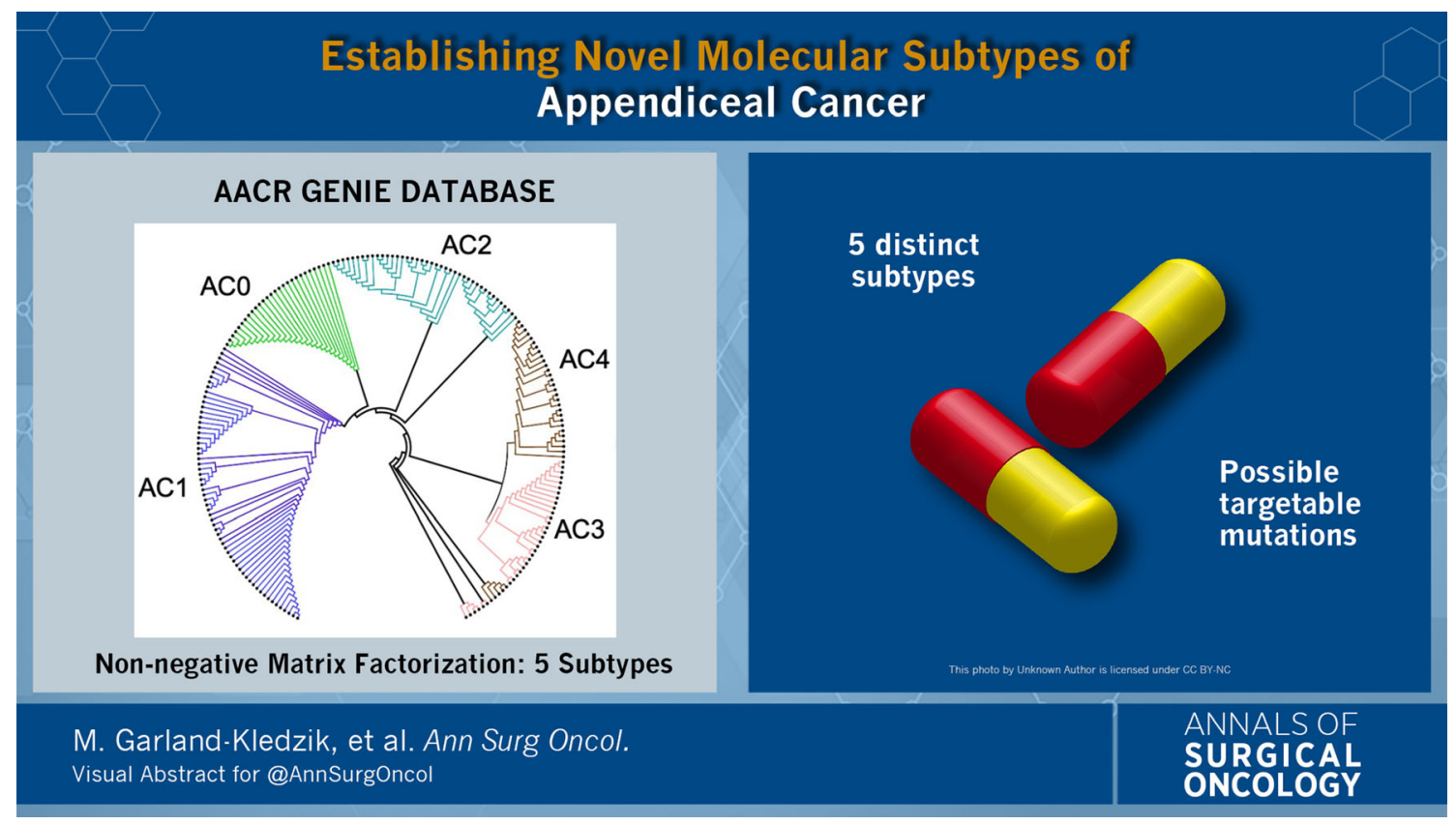

This was previously presented at SSO's Advanced Cancer Therapies, February 2020, Orlando, FL.

(C) Society of Surgical Oncology 2021

M. Garland-Kledzik, MD

e-mail: mgkledzikmd@gmail.com; Molly.kledzik@hsc.wvu.edu
DISCLOSURE The authors declare that they have no conflict of interest

Publisher's Note Springer Nature remains neutral with regard to jurisdictional claims in published maps and institutional affiliations. 